\title{
Laparoscopy-Assisted Distal Gastrectomy for Early Gastric Cancer: A Video Demonstration
}

\author{
Seigo Kitano, MD, Tsuyoshi Etoh, MD, Masafumi Inomata, MD, and Norio Shiraishi, MD \\ Department of Surgery I, Oita University Faculty of Medicine, Oita, Japan
}

\begin{abstract}
Background. Laparoscopic gastrectomy with lymph node dissection, such as laparoscopy-assisted distal gastrectomy (LADG), has been widely accepted as the treatment for early gastric cancer with the risk of lymph node metastasis, especially in Asia since 1991. ${ }^{1-3}$

Purpose. We demonstrate our standard techniques for LADG with lymph node dissection and show their pitfalls during operation.

Procedures and Pitfalls. This is a case presentation of a 61-year-old man with early gastric cancer of the gastric body who underwent LADG with D1+ suprapancreatic lymph node dissection. The principles of this procedure are shown in this video. To prevent operative complications, appropriate use of forceps and instruments, such as a vessel-sealing system, ultrasound coagulation devices, and circular or linear staplers is important in laparoscopic procedures. In addition, an appropriate approach to layers and vessels is needed. In general, the major intraoperative complications during LADG are bleeding, and the major postoperative complications are anastomotic problems, including stenosis or leakage. Previous reports have demonstrated that the risk factors of complications in LADG were comorbidities, the surgical experience, and visceral fat. $^{4-6}$
\end{abstract}

Electronic supplementary material The online version of this article (doi:10.1245/s10434-011-1759-3) contains supplementary material, which is available to authorized users.

(C) Society of Surgical Oncology 2011

First Received: 22 June 2010;

Published Online: 2 July 2011

S. Kitano, MD

e-mail: kitano@oita-u.ac.jp
Conclusions. LADG for early gastric cancer is a relatively safe and effective procedure. To achieve laparoscopic gastrectomy more safely, the surgeons must try to prevent intra- or postoperative complications.

\section{REFERENCES}

1. Kitano S, Iso Y, Moriyama M, Sugimachi K. Laparoscopy-assisted Billroth I gastrectomy. Surg Laparosc Endosc. 1994;4:146-8.

2. Yang H-K. Laparoscopic gastric surgery in Asia. Asian J Endosc Surg. 2008;1:11-3.

3. Etoh T, Shiraishi N, Kitano S. Current trends of laparoscopic gastrectomy for gastric cancer in Japan. Asian J Endosc Surg. 2009;2:18-23.

4. Kitano S, Shiraishi N, Uyama I, Sugihara K, Tanigawa N, Japanese Laparoscopic Surgery Study Group. A multicenter study on oncologic outcome of laparoscopic gastrectomy for early cancer in Japan. Ann Surg. 2007;245:68-72.

5. Kim MC, Kim W, Kim HH, Ryu SW, Ryu SY, Song KY, Lee HJ, Cho GS, Han SU, Hyung WJ. Risk factors associated with complication following laparoscopy-assisted gastrectomy for gastric cancer: a large scale Korean multicenter study. Ann Surg Oncol. 2008;15:2692-700.

6. Kim HH, Hyung WJ, Cho GS, Kim MC, Han SU, Kim W, Ryu SW, Lee HJ, Song KY. Morbidity and mortality of laparoscopic gastrectomy versus open gastrectomy for gastric cancer: an interim report-a phase III multicenter, prospective, randomized Trial (KLASS Trial). Ann Surg. 2010;251(3):417-20. 